Title: The impact of question type and empathy on police interviews with suspects of homicide, filicide and child sexual abuse.

Running title: Police interviews with murderers and sex offenders

Authors: Gavin Oxburgh ${ }^{1,2}$; James Ost ${ }^{3}$; Paul Morris $^{3}$; Julie Cherryman ${ }^{3}$

Note: This is a post print of the article published in Psychiatry, Psychology \& Law (DOI: 10.1080/13218719.2014.918078). It is not the copy of record and, as such, may contain typographical or other minor errors not present in the published version.

\footnotetext{
${ }^{1}$ School of Psychology, Newcastle University, 1 Queen Victoria Road, Newcastle-upon-Tyne, NE1 7RU, UK. E-mail: gavin.oxburgh@ncls.ac.uk

${ }^{2}$ Corresponding author

${ }^{3}$ Department of Psychology, University of Portsmouth, King Henry Building, King Henry 1 Street, Portsmouth PO1 2DY, UK.
} 


\title{
The impact of question type and empathy on police interviews with suspects of homicide, filicide and child sexual abuse.
}

\begin{abstract}
Conducting interviews with 'high-stake' offenders, especially those accused of murder and sexual offences, represents a complex and emotive area of work for police officers. Using an English sample of fifty-nine actual police interviews, the effects of empathy and question type on the amount of investigation relevant information obtained from interviews with suspects of child murder, child sex offences and adult murder were analysed and compared. No direct effects of empathy on the amount of information elicited was found, however, in interviews classified as empathic, interviewers asked significantly more appropriate questions than they did in interviews classified as non-empathic, and significantly more items of information were elicited from appropriate questions. There was a significant effect of offence type on the number of inappropriate, questions asked, with significantly more inappropriate questions being asked in interviews with suspects of child sex offences than they did in interviews with suspects of child or adult murder.
\end{abstract}

Key words: Empathy, questions, interviews, sexual offences, murder 


\section{Introduction}

Obtaining complete, accurate and reliable information from victims, witnesses and suspected offenders (hereinafter referred to as 'suspects') is central to any criminal investigation, and the police interview is key to obtaining such information (Milne \& Bull, 1999; Walsh \& Oxburgh, 2008; Oxburgh \& Ost, 2011). The effective interviewing of suspects is especially important in interviews concerning 'high-stake' crimes (e.g., sexual offences \& murder) where suspects have a great deal to lose if they admit their involvement (Gudjonsson, 2006). Such cases are also demanding for the interviewer and, perhaps unsurprisingly, police officers report such interviews as being more emotive and problematic than other interviews they conduct (Holmberg \& Christianson, 2002; Kebbell, Hurran \& Mazerolle, 2006; Oxburgh, Williamson \& Ost, 2006; Oxburgh, Ost, Morris \& Cherryman, 2013).

Soukara, Bull and Vrij (2002), for example, found that officers who interviewed suspects of child rape reported that they became 'stressed' during such interviews and would only show empathy towards the suspect after they had confessed to the crime in question. Furthermore, police officers who regularly interview individuals suspected of child murder and child rape consider those interviews to be more stressful than when the victim is an adult (see Oxburgh, et al., 2013). One explanation for these findings could be that police officers are regularly exposed to stressful incidents and have to deal with highly emotive and sometimes gruesome evidence, which may make the subsequent interviews with suspects more difficult to conduct (Mitchell-Gibbs \& Joseph, 1996; Oxburgh, et al. 2006; 2013). This is especially so if those officers involved suffer with vicarious traumatisation from accumulated trauma-related events, which could influence their attitudes towards suspects 
(Saakvitne \& Pearlman, 1996; Pearlman \& MacIan, 1993). Indeed, Holmberg (2004) found that officers who had been exposed to traumatising events held more negative attitudes when interviewing suspects of sexual offences, and that stressful event exposure was directly related to police officers' self-reported negative attitudes towards interviewing such suspects - this may well only serve to generate some kind of avoidance to the suspect (Chen \& Bargh, 1999).

This generated avoidance can be explained by the ego-defensive function of attitudes (Katz, 1960). An individual's ego-defensive function includes the devices by which a particular individual (in this case, a police interviewer) avoids facing their inner and outer realities of the dangers the world holds for them. When an individual cannot admit to themselves that they have deep feelings towards another person, or what they stand for (in this case a suspected sex offender), they may bolster their ego by displaying attitudes of superiority towards the other person or group. This may well culminate in an officer showing 'dominance' in the interview room - three other factors may also emerge: (i) control; (ii) speed, and; (iii) power (see Oxburgh \& Ost, 2011). In other words, the interviewer may have a perception that $\mathrm{s} / \mathrm{he}$ must remain in control of the interview by asking mostly closed (or other inappropriate forms of questions - see following section). In the case of sex offenders, officers may find the offence details disclosed by the suspect distasteful so, to counteract this, s/he may try to limit their emotional exposure to them. This form of interview also enables the interviewer to conduct the interview with speed, which reduces physical and psychological exposure to the suspect. Lastly, rather than showing empathy to the suspect, if the interviewer remains 'dominant' and asks questions that are mostly closed in nature, there is no opportunity for the suspect to try and rationalise his/her behaviour and thus, takes away the suspect's perceived power. 
In the present study, two measures of interview 'quality' were employed. The first focused on the extent to which the interview could be described as having been conducted in an empathic manner (see Holmberg \& Christianson, 2002; Kebbell et al., 2006; Oxburgh \& Ost, 2011), and the second focused on the balance of appropriate to inappropriate questions used by the interviewing officer. The potential impact of each of these measures on the quality of an investigative interview is outlined below.

\section{Empathic interviewing styles}

There have been many definitions of empathy posited by academic researchers in both psychological and medical-related journals (see Barrett-Lennard, 1981; Baron-Cohen, 2011; Barone et al. 2005; Gladstein, 1983; Davis, 1983; Preston \& de Waal, 2002). In its broadest sense, Greenson (1967) argues that empathy means to, "share and experience" (p.368) the feelings of another human being. Reactions could range from just simply understanding the other person's perspective (e.g., a cognitive or intellectual reaction) to a more intuitive or emotional reaction (Davis, 1983). However, in a police context, empathy is also about having the ability to understand the perspective of the interviewee, to also appreciate the emotions and distress of that person, and to communicate that directly, or indirectly, to the interviewee (Davis, 1983). In other words, empathy can be seen as a multi-dimensional phenomenon comprising both cognitive processes and emotional (or affective) capacities (Barrett-Lennard, 1981; Joliffe \& Farrington, 2004; Larden, Melin, Holst \& Langstrom, 2006). However, despite the principles of ethical interviewing posited by Shepherd (1991), which emphasises the use of empathy, there have been relatively few academic studies to date that have analysed the use of empathy in actual police interviews (but see Holmberg \& Christianson, 2002; Kebbell et al., 2006; Oxburgh, Ost \& Cherryman, 2012), and none where 
the interviews have involved both children and adults as victims, involving murder and sexual offences. The present study aims to fill that void.

Holmberg and Christianson (2002) analysed suspects' perceptions of interviewers' use of empathy during police interviews and found that sexual offenders reported less empathy (and more negative behaviour) from police officers during their interviews than murderers. As a result, Holmberg and Christianson categorized police interviewing techniques into one of two styles: (i) dominant, or; (ii) humane. The dominant approach was characterized by impatience, aggressiveness, hostility and condemnation, whereas the humane approach (e.g., friendly, empathic, co-operative and personal) was associated with more admissions by the suspected offender.

Kebbell et al. (2006) found that offenders were more likely to report that they would have confessed to their crime had the police shown empathy towards them and treated them with humanity during the interview. However, both Holmberg and Christianson (2002) and Kebbell et al. (2006) rely on offenders' self-reports of what they would have done had they been interviewed in a more empathic manner. Such a methodology has limitations. In the present study, we coded real-life interviews with suspects to establish whether empathy has any relation to the 'quality' of the information obtained. Our model, which is based on the theoretical principles of the 'empathy cycle' outlined by Barrett-Lennard (1981; see Figure 1), focuses on three key variables (empathic opportunities, continuers \& terminators) and a fourth variable that we have added and which we refer to as spontaneous empathy. But how might such variables emerge during a police interview? 
During a police interview, a suspect might provide some kind of empathic information, consciously or otherwise, in the hope that the interviewer will respond. For example s/he might say, “I'm finding this very difficult and I don't know what to do". This would be coded as an empathic opportunity - in other words, the suspect is providing the interviewer with an opportunity to respond. At this point, the interviewer has one of two ways to deal with this information. Firstly, s/he can resonate some, or all aspects, of the information received (e.g., "That's okay, I understand") and continue the empathic opportunity presented. Alternatively, s/he could ignore the comments made or information received completely, or ask an unrelated question in response, thus terminating the empathic opportunity. Finally, an interviewer could spontaneously make remarks of an empathic nature (e.g., "I know this must be really difficult for you, however..."). In their study, and using the above model, Oxburgh et al. (2012) analysed 26 actual English police interviews with suspects of child rape and found, firstly, that the use of empathy in interviews was generally very low. Secondly, they found that questioning strategy (the use of appropriate versus inappropriate questions) appeared to be more important than an empathic approach per se in eliciting relevant information from suspects. However, it is not clear whether those findings were unique to that particular sample of suspects - those that we know interviewing officers find it challenging to conduct interviews with. In the present study, we wanted to establish if the same pattern would emerge when interviews with suspects of child sex offences are compared to interviews with suspects of other 'high stake' crimes (e.g., child and adult murder)? In order to compare the findings of the present study to those of previous research (e.g., Oxburgh et al., 2012), the types of questions used by interviewers were also coded. 


\section{Question typologies}

A large body of academic literature has focused on the effectiveness of different questioning techniques used during police interviews with children and adults, whether witnesses or suspected offenders (e.g., Clarke \& Milne, 2001, Clarke, Milne \& Bull, 2011; Lamb, Hershkowitz, Sternberg, Boat \& Everson, 1996; Milne \& Bull, 1999; Myklebust \& Bjørklund, 2006, 2009; Oxburgh et al., 2012, 2013; Powell \& Snow, 2007; Shepherd, 2007; Shepherd \& Griffiths, 2013). There is now overwhelming acceptance that using open-ended questions (e.g., those starting with 'Tell', 'Explain', 'Describe') encourage interviewees (adults and children) to freely recall events, which, in turn, are also associated with more full and accurate accounts (Aldridge \& Cameron, 1999; Cederborg, Orbach, Sternberg \& Lamb, 2000; Davies, Westcott \& Horan, 2000; Griffiths \& Milne, 2006; Korkman, Santilla \& Sandnabba, 2006; Lamb et al., 1996; Loftus, 1982; Milne \& Bull, 1999, 2006; Moston, Stephenson \& Williamson, 1993; Myklebust \& Bjørklund, 2006; Pipe, Lamb, Orbach, \& Esplin, 2004; Powell \& Snow, 2007; Shepherd, 2007; Sternberg, Lamb, Esplin, Orbach, \& Hershkowitz, 2002). Such accounts should then be followed by more 'probing' forms of questions (e.g., 5WH questions - 'what', 'when', 'where', 'why', 'who' and 'how'). Indeed, these forms of questioning are undoubtedly the most productive or appropriate to use in all police interviews (see Oxburgh et al., 2012). Conversely, inappropriate questions, including those classified as closed, encourage interviewees to respond on the basis of recognition memory, rather than on the basis of free recall, which can dramatically increase the probability of error in the answers provided (Dent, 1982, 1986; Dent \& Stephenson, 1979; Lamb \& Fauchier, 2001; Orbach \& Lamb, 2001; for a review see Oxburgh, Myklebust \& Grant, 2010). 
In order to address these issues, in the present study, each question that was asked by an interviewer was coded (see Method section) and then classified as either appropriate or inappropriate. The proportion of appropriate and inappropriate questions was then calculated for each interview to see if this had any impact on the amount of information obtained.

Based on psychological theory and findings from previous research, we hypothesised that: (i) interviews in which empathy was used by an interviewer would not contain more items of relevant information than non-empathic interviews; (ii) that responses to appropriate questions would contain more items of relevant information than responses to inappropriate questions; (iii) empathy would be less prevalent in child sex offences interviews compared to interviews with suspects of child and adult murder, and finally, (iv) that interviews which were classified as empathic would contain more appropriate questions. The reason for focusing on these crimes is that they are most likely the hardest for the suspect to admit to and discuss at interview (see Gudjonsson, 2006).

\section{Method}

\section{Sample}

Following the receipt of all necessary ethical approval, one large English police force agreed to provide audio-tapes and transcripts of actual interviews $(\mathrm{N}=59)$ with suspects of child murder $(n=20)$, child sex offences $(n=20)$ and adult murder $(n=19)^{1}$, all of which were

\footnotetext{
${ }^{1}$ These data are unique and have not been used in any previous research.
} 
conducted between 2003 and 2007. In some interviews, there were solicitors ${ }^{2}$, appropriate adults and interpreters present in addition to the interviewing officers (see table 1).

Insert table 1 about here

In accordance with the Professionalising the Investigation Programme (PIP) in England and Wales, all participating officers had to be at least PEACE PIP level two ${ }^{3}$ and regularly employed on investigations that involved the aforementioned crimes. PEACE is the mnemonic acronym given to the model of interviewing used in England and Wales and other countries (including Norway, Australia and parts of Canada; Planning and Preparation; Engage and Explain, Account; Closure, Evaluation) (e.g., Clarke \& Milne, 2001, Clarke et al., 2011; Milne \& Bull, 1999). For legal reasons, all interviews in our sample were from investigations that had been categorised as 'closed' and had already been processed through the judicial system. The participating police force provided additional information including: (i) interview length; (ii) the interviewing officers' gender; (iii) additional persons present, and; (iv) the gender of the victim.

\section{Coding of interviews}

The interviews $(\mathrm{N}=59)$ were received in paper format, with accompanying audiotapes, and, following full anonymisation, detailed coding took place. The first variable coded was the presence of empathy. For the purpose of the present analyses, an empathic interview was defined as one containing at least one empathic opportunity that was continued, or one

\footnotetext{
2 In England \& Wales, all suspects are entitled to have a solicitor or other legal representative present during their police interview.

3 In England \& Wales, under the 2007 Professionalising the Investigation Programme (PIP), there are four 'levels' of PEACE interview training for officers, with PIP Level 2 being for dedicated investigators (e.g., detectives) who plan, conduct and evaluate interviews with suspects for serious and complex investigations.
} 
which contained spontaneous empathy - when officers use empathy without any prompting (or opportunities) from the suspect. Examples of empathic exchanges between interviewer and interviewee in each category (e.g., opportunities, continuers, terminators, and spontaneous empathy) are provided in table 2. The number of instances of spontaneous empathy, empathic opportunities, continuers, and terminators were counted in each interview.

Insert table 2 about here

The next set of variables coded was the type of questions used by the interviewers. These were categorised into nine sub-types, divided into the two broad categories of appropriate and inappropriate. The number and type of questions were counted for each interview. A full breakdown of each question type is available in table 6 .

The final variable coded was the amount of investigation relevant information obtained during the interview. The coding scheme was adapted from those used in previous studies (e.g., Hutcheson, Baxter, Telfer \& Warden, 1995; Lamb et al., 1996; Milne \& Bull, 2003; Yuille \& Cutshall, 1986 - see also Oxburgh et al., 2012). The scheme included items in the following categories: Person information; Action information; Location information; Item information; and Temporal information. Each item of information was counted once and repetitions, as in previous studies, were ignored. All items of information elicited in each category were summed to provide a total score for that category and all categories were then summed to provide a total information score. 
Four raters independently coded $30 \%$ of the transcripts, including: (i) question type; (ii) prevalence of empathy; and, (iii) amount and type of IRI. Inter-rater reliability was assessed using the percentage of agreement method and was $94 \%$, which was deemed acceptable.

\section{Description of sample}

Initial analysis of the interviews found no evident breaches of the Police and Criminal Evidence Act (PACE) Act (1984) (e.g., nothing said or done which would make the interviews inadmissible in evidence). Although two police officers were present in each interview, only the details relating to the main interviewer were recorded. A total of 44 interviews $(75 \%)$ were conducted by male officers, with $15(25 \%)$ conducted by female officers. The mean lengths of the interviews were: (i) child murder $=74 \mathrm{mins}(\mathrm{SE}=9.76$, range $12-169 \mathrm{mins})$; (ii) child sex offences $=80.25 \mathrm{mins}(\mathrm{SE}=13.01$, range $15-203 \mathrm{mins})$; (iii) adult murder $=115.11 \mathrm{mins}(\mathrm{SE}=16.70$, range $28-315 \mathrm{mins})$.

\section{Results}

\section{Data screening}

As expected with real life data, exploratory analyses revealed wide variation in interview length ( $\mathrm{M}=89$ minutes, range 12 - 315 minutes in length). To control for these differences, the number of each question type, instances of empathy, and the amount of investigation relevant information reported was corrected for length of interview. In addition,

\footnotetext{
${ }^{4}$ The PACE Act is the primary legislation in England and Wales for the detention and treatment of suspected offenders.
} 
given that not all parametric assumptions were met, non-parametric analyses were used throughout.

\section{General}

The second step in the analysis was to check for any systematic differences between 'comment' and 'no comment' interviews 5 . In other words, was there anything systematic about either the type of offence, the gender of the interviewing officer, or the presence of a solicitor that might have led to a particular suspect choosing to utilise their right to go "no comment'? The breakdown of 'comment' and 'no comment' interviews are detailed in table 3. For the purposes of the analyses presented below, denials, partial confessions and full confessions were coded as 'comment' interviews.

Insert table 3 about here

The first point to note is that there was a solicitor present in all 23 cases where an interviewee exercised their right to say nothing. In contrast, nine out of the 36 'comment' interviews (4 denials and 5 full confessions) were conducted with no solicitor present. Chisquare analyses revealed that the offence type was not associated with whether the interviewee decided to say nothing during their interviews $\left(\chi^{2}(2, N=59)=1.06, p>.05\right)$, and neither was the gender of the interviewer $\left(\chi^{2}(1, N=59)=.07, \mathrm{p}>.05\right)$, nor the gender of the interviewee $\left(\chi^{2}(1, N=59)=.02, \mathrm{p}>.05\right)$.

\footnotetext{
${ }^{5}$ In England and Wales, persons being formally interviewed as a suspect have a fundamental right in law not to answer any questions put to them by the police, although a court may draw an inference from their silence. These are referred to as 'No Comment' interviews.
} 


\section{The amount of investigation relevant information reported}

The next step of our exploratory analysis was to establish the amount of relevant information reported during each interview as a function of offence type. For this analysis, all no comment interviews $(n=23)$ were excluded (because in no comment interviews, no IRI would be present). The remaining 36 interviews contained a total of 7,742 items of relevant information $(\mathrm{M}=215.06, \mathrm{SE}=22.75)$, which was broken down by offence type as follows: child murder $(n=11, \mathrm{M}=207.55, \mathrm{SE}=29.77)$; child sex offences $(n=14, \mathrm{M}=203.64, \mathrm{SE}=41.55)$; adult murder $(n=11, \mathrm{M}=237.09, \mathrm{SE}=45.99)$.

Insert table 4 about here

Although, as shown in Table 4, interviewees reported more 'person' details across all offence types than any other type of relevant information, Kruskal-Wallis tests revealed that the number of items of relevant information reported by the interviewee did not differ significantly as a function of offence type: Person information $(H(2)=2.96 ; \mathrm{p}>.05)$; Action information $H(2)=1.58 ; \mathrm{p}>.05)$; Location information $(H(2)=4.79 ; \mathrm{p}>.05)$; Item information $(H(2)=3.05 ; \mathrm{p}>.05)$; Temporal information $(H(2)=2.14 ; \mathrm{p}>.05)$; Total relevant information $(H(2)=4.07 ; \mathrm{p}>.05)$.

\section{The presence of empathy in interviews}

The next aspect of the analysis focussed on the presence of empathy. In the current sample, $39(66 \%)$ of the 59 interviews did not contain any examples of opportunities, continuers or terminators and, thus, statistical analyses were not possible using these variables. Interviews were instead categorised as 'empathic' or not, on the basis of whether 
they contained any instances of spontaneous empathy. This is because even in a 'no comment' interview, the interviewer still has the opportunity to display spontaneous empathy whereas, in a 'no comment' interview, no empathic opportunities (i.e., from the suspect) will present themselves to be either continued or terminated. Spontaneous empathy was scored dichotomously (Yes/No; see Oxburgh \& Ost, 2011; Oxburgh et al., 2012). From the total sample $(\mathrm{N}=59), 25$ interviews $(42 \%)$ contained at least one instance of spontaneous empathy.

Chi-square analysis was conducted to establish if there was any relationship between the interviewing officers' use of spontaneous empathy and the offence type the suspect was being interviewed about. Although non-significant $\left(\chi^{2}(2)=3.97 ; \mathrm{p}>.05\right)$, there was a trend for interviewing officers to exhibit fewer examples of spontaneous empathy in child sex offence interviews $(N o=15 ; Y e s=5)$, compared to adult murder $(N o=10 ; Y e s=9)$ and child murder $(N o=9 ; Y e s=11)$ interviews.

\section{Empathy and investigation relevant information}

The next analysis was conducted to establish whether interviews, which were categorised as empathic, contained more items of relevant information than those that were not. For this analysis, all no comment interviews $(n=23)$ were excluded (because in no comment interviews, no relevant information would be present). A series of Mann-Witney tests revealed no significant differences between interviews containing instances of spontaneous empathy and those that did not based on the number of items of IRI reported by the interviewee: Person information $\left(U=111 \mathrm{~N}^{1}=25, \mathrm{~N}^{2}=15, \mathrm{p}=.136\right)$; Action information $\left.U=138, \mathrm{~N}^{1}=21, \mathrm{~N}^{2}=15, \mathrm{p}=.531\right)$; Location information $U=113, \mathrm{~N}^{1}=21, \mathrm{~N}^{2}=15, \mathrm{p}=.153$ ); Item information $\left.U=136.50, \mathrm{~N}^{1}=21, \mathrm{~N}^{2}=15, \mathrm{p}=.500\right)$; Temporal information $U=138, \mathrm{~N}^{1}=21$, 
$\mathrm{N}^{2}=15, \mathrm{p}=.531$ ); Total relevant information $\left.U=131.50, \mathrm{~N}^{1}=21, \mathrm{~N}^{2}=15, \mathrm{p}=.395\right)$. The mean total relevant information in each empathic interview (corrected for interview length) is shown in table 5.

Insert table 5 about here

\section{The use of appropriate and inappropriate questions}

Questions were broadly categorised into nine different types, which were then divided into appropriate and inappropriate categories, with the number and type of questions counted for each interview (see Table 6). A Wilcoxon analysis revealed that more inappropriate questions were asked in each interview (corrected for interview length) than appropriate questions $(W(58)=59, \mathrm{Z}=-5.95, \mathrm{p}<.001)$ and this held for both 'comment' $(W(35)=36, Z=-4.66, p<.001)$ and 'no comment' interviews $(W(22)=23, Z=-3.832, p<.001)$. Insert table 6 about here

Our next analysis focussed on whether officers used more appropriate or inappropriate questions dependent upon the type of offence. Focusing on the 'comment' interviews first $(n=36)$, two Kruskal-Wallis tests revealed no significant difference in the use of appropriate questions $(H(2)=0.54 ; \mathrm{p}>.05)$, but a significant difference was evident in the number of inappropriate questions $(H(2)=8.25 ; \mathrm{p}<.05)$ as a function of offence type. Specifically, in 'comment' interviews, interviewers asked more inappropriate questions in child sexual offences interviews, followed by adult murder interviews, then child murder interviews. Bonferroni-corrected Mann-Whitney tests revealed significant differences 
between child sex offences and child murder $(U=106.00, p<.05, r=-.40)$, but no significant difference between child sex offences and adult murder $(U=152.00, p=.29, r=-.16)$, or between child murder and adult murder $(U=159.00, p=.384, r=-.14)$. This means that interviewers ask significantly more inappropriate questions with suspects of child sex offences than suspects of child and adult murder.

In relation to the 'no comment' interviews $(n=23)$, further independent samples Kruskal-Wallis tests were conducted, which revealed no significant differences in either appropriate $(H(2)=0.42 ; \mathrm{p}>.05)$ or inappropriate $(H(2)=4.13 ; \mathrm{p}>.05)$ questions as a function of offence type. In order to establish if one category of question elicited higher amounts of relevant information (e.g., appropriate or inappropriate), all 'no comment' interviews ( $n=23)$ were excluded from the analysis (because in these cases, no relevant information would be present). A Wilcoxon test revealed that in 'comment' interviews, significantly more items of relevant information were elicited from appropriate questions $(\mathrm{M}=1.53, \mathrm{SE}=.173)$ than inappropriate questions $(\mathrm{M}=.93, \mathrm{SE}=.083)(W(35)=36, \mathrm{Z}=-3.69, \mathrm{p}<.001)$.

Finally, we wanted to establish if interviewers who spontaneously showed empathy also used different question types. A Mann-Whitney test on the entire sample $(\mathrm{N}=59)$ revealed that interviews which contained examples of spontaneous empathy also contained a higher number of appropriate questions $(\mathrm{M}=1.66, \mathrm{SE}=.188)$, than those interviews that did $\operatorname{not}(\mathrm{M}=1.14, \mathrm{SE}=.161)\left(U=262, \mathrm{~N}^{1}=34, \mathrm{~N}^{2}=25, \mathrm{p}<.05\right)$. There was no difference in the number of inappropriate questions asked as a function of whether the interview was rated as containing examples of spontaneous empathy $(\mathrm{M}=2.73, \mathrm{SE}=.293)$ or not $(\mathrm{M}=2.64, \mathrm{SE}=.272)$ $\left(U=390, \mathrm{~N}^{1}=34, \mathrm{~N}^{2}=25, \mathrm{p}>.05\right)$. 


\section{Discussion}

Given the limited research that has previously been conducted on interviews relating to suspects of sexual offences and murder, and the 'apparent' usefulness of empathy in investigative interviews (Holmberg \& Christianson 2002; Kebbell et al., 2006; see also Benneworth, 2007), the overall aim of the present study was to establish the efficacy of empathy and question type during real-life interviews of suspects of high-stake crimes, and whether this had any impact on the amount of relevant information elicited. In summary, in interviews where the suspect chose to answer questions, there was no difference in the number of appropriate questions asked of interview as a function of offence type. However, interviewers asked significantly more inappropriate questions in interviews with suspects of child sex offences, than child murder. In those interviews where the suspect utilised his/her right to say nothing during the interview, no differences were found in the number of appropriate or inappropriate questions asked as a function of offence type. Interviews in which spontaneous empathy was shown by the interviewer did not contain any more items of relevant information than those interviews in which spontaneous empathy was not shown. The conclusion, at least in the present sample, is that across all three offence types, the use of appropriate question types appears to be more beneficial in eliciting a greater amount of relevant information than the use of empathy per se.

Although research in this area is limited, there are two distinct strands emerging, with some focusing on either the offenders' perspective of the interview process (e.g., Holmberg \& Christianson, 2002; Kebbell et al., 2006), the obtaining of confessions (Beauregard, Deslauriers-Varin, \& St-Yves, 2010; Kebbell, Alison \& Hurren, 2008), or both. The present authors would argue that, in line with the principles of ethical interviewing, the primary goal 
of an investigative interview is not to obtain a confession per se, rather, it is to obtain accurate, relevant and complete accounts to provide the investigation team with relevant information to enable them to proceed with their enquiry (Milne \& Bull, 1999; Williamson, 1993). Whilst the importance of the suspect's perspective of their police interviews must be acknowledged, the analysis of actual interviews is paramount and provides vitally important data that can be used to assist police forces worldwide on how to improve their interviews.

\section{The presence of empathy}

Fewer than half the interviews $(n=20 ; 34 \%)$ contained empathic opportunities and so, instead, we classified an interview as being empathic if it contained at least one occurrence of spontaneous empathy. However, there was no significant difference in the occurrence of spontaneous empathy as a function of offence type, although there was a trend toward officers showing this type of empathy most frequently in child murder interviews, and least frequently in child sex offence interviews. This offers some support for the findings by Holmberg and Christianson (2002) and Kebbell et al. (2006) because they too found that in interviews of suspected murderers, officers were more 'humane' towards the suspected offenders than in cases of child sexual offences. Despite these trends, no significant differences were found in the amount of relevant information elicited as a function of whether the interview was classified as empathic or not. As such, no evidence was found to support the overall arguments made by Holmberg and Christianson (2002) and Kebbell et al. (2006) that empathic interviews should be 'better' on some measure than non-empathic ones. Of course, this could be due to various factors, including: (i) the relatively low use of empathy in the present study - which is worthy of note in itself; (ii) that the definition of empathy put forward in the present study does not capture what Holmberg and Christianson, and Kebbell 
et al. meant by empathy, and; (iii) that in the present study, confessions by the suspect were not included in the analysis (contrary to the studies by Holmberg and Christianson, and Kebbell et al). This was because in England and Wales, where the present study was conducted, police officers do not conduct investigative interviews to obtain confessions (Milne \& Bull, 1999).

Of course, empathy is not just about counting the number of times spontaneous empathy is used (or counting the number of empathic opportunities, continuers and terminators within interviews) - it is a far more complex psychological construct than we have been able to capture from interview transcripts and audio-tapes (see Barrett-Lennard, 1981; Baron-Cohen, 2011; Barone et al. 2005; Gladstein, 1983; Davis, 1983). Neither is an empathic (or non-empathic) approach confined solely to the interview room, rather, researchers need to consider other important aspects, including the arrest and custody procedure which takes place before the investigative interview is undertaken - such processes could have a dramatic effect on the subsequent investigative interview. That said, the present research is the first to attempt to capture the empathic interviewing approach using audiotapes and transcripts of actual interviews with suspects of murder and sexual offences.

\section{Question typologies}

In line with existing research (e.g., Davies et al., 2000; Myklebust \& Bjorklund, 2009; Oxburgh et al., 2012), we found that significantly more items of relevant information were elicited from appropriate questions than inappropriate questions. We also found that where suspects chose to answer questions (e.g., 'comment' interviews), there was a significant effect of offence type on the number of inappropriate questions asked. In those interviews 
where suspects refused to answer questions (e.g., where they utilised their right to go 'no comment'), there was no difference in the use of appropriate or inappropriate questions. We also found that interviews that contained more empathy also contained more appropriate questions. However, this finding needs to be interpreted cautiously because it is not known whether such a relationship is causal (e.g., empathic interviews 'cause' officers to use more appropriate questions) or whether another variable was operating (e.g., officers who use more empathy, also use more appropriate questions perhaps by virtue of their personality, training or prior experience with that type of offender; e.g., Rich \& Seffrin, 2012).

\section{Limitations of study and future directions}

Although this study was based on actual police interviews of persons accused of committing 'high-stake' crimes, these data were obtained from only one large English police force and the sample size was relatively small $(\mathrm{N}=59)$. Although all interviews in the sample had accompanying audio-recordings, there were no video-recordings and thus, we were only able to analyse question type, empathy and information obtained on a purely literal level (Dickson \& Hargie, 2006), which is somewhat limited. This is because relevant factors might well be present (and code-able) from video recordings of interviews that cannot be coded from audio-tapes or transcripts (e.g., non-verbal communication). It is recommended that future research should not just focus on the investigative interview by counting question types, incidents of empathy and the amount of relevant information elicited, but should include non-verbal communication (from the police and suspect) from the initial arrest, custody procedure, through to, and including, the final interview. Such research could also include question semantics (e.g., the content) and pragmatics (e.g., the intent) to provide more detailed and deeper analyses (Oxburgh et al., 2010). This will ensure research 
encapsulates the entire process and not just one aspect. We accept, however, that this could be difficult given the nature and sensitivity of such cases and the problems associated with academic researchers obtaining access to relevant and meaningful data.

\section{Recommendations for practice}

Given the lack of ecologically valid research on the efficacy of empathy in police interviews to obtain relevant information, it is perhaps understandable why police officers appear to receive very little training (if any) on the usefulness of it. According to the psychomedical literature, there is no doubt that empathy can be an effective tool, however, practitioners can only develop the skill if properly instructed on the processes involved (Barone et al., 2005). Unfortunately, as shown by Oxburgh et al. (2013), there appears to be no clear understanding of the definition of empathy by police officers. The present research has found that use of empathy is limited in police interviews and its effectiveness in obtaining increased items of relevant information questionable. Thus, before advising that empathy is a useful tool, further research should be conducted.

\section{Conclusion}

The present study showed that the spontaneous use of empathy (by itself) by police interviewers had no impact on the amount of relevant information obtained in interviews with suspected offenders of child murder, child sex offences and adult murder, but when used with appropriate questions, the results on information obtained were significant. This replicates the findings of Oxburgh et al. (2012), but fails to support the suggestions of Holmberg and Christianson (2002) and Kebbell et al. (2006) that using empathy, by itself, in interviews 
might produce some kind of better quality interview - however, as previously stated, this finding should be treated cautiously. The present research also supports previous research regarding the use of different question types, which suggests that asking appropriate questions in interviews leads suspects to disclose significantly higher amounts of information that may be relevant to the investigation (see Myklebust \& Bjorklund, 2006, 2009; Oxburgh et al., 2012; Phillips, Oxburgh, Gavin \& Myklebust, 2011).

\section{References}

Aldridge, J., \& Cameron, S. (1999). Interviewing child witnesses: Questioning techniques and the role of training. Applied Developmental Science, 3, 136-147.

Baron-Cohen, S. (2011). Zero degrees of empathy: A new theory of human cruelty. Milton Keynes: Penguin Books.

Barrett-Lennard, G. T. (1981). The empathy cycle: Refinement of a nuclear concept. Journal of Counselling Psychology, 28, 91-100.

Barone, D. F., Hutchings, P. S., Kimmel, H. J., Traub, H. L., Cooper, J. T., \& Marshall, C. M. (2005). Increasing empathic accuracy through practice and feedback in a clinical interviewing course. Journal of Social and Clinical Psychology, 24, 156-171.

Beauregard, E., Desl auriers-Varin, N., \& St-Yves, M. (2010). An investigation of the interactions between factors related to the decision of sex offenders to confess or not during police interrogation: A classification tree approach. Sexual Abuse: A Journal of Research and Treatment, 22, 343-367. 
Benneworth, K. (2007). Repertoires of paedophilia: Conflicting descriptions of adult-child sexual relationships in the investigative interview. The International Journal of Speech, Language and the Law, 13, 189-211.

Cederborg, A. C., Orbach, Y., Sternberg, K. J., \& Lamb, M. E. (2000). Investigative interviews of child witnesses in Sweden. Child Abuse and Neglect, 24, 1355-1361.

Clarke, C., \& Milne, R. (2001). National evaluation of the PEACE investigative interviewing course. Police Research Award Scheme Report PRAS/149.

Clarke, C., Milne, R., \& Bull, R. (2011). Interviewing suspects of crime: The impact of PEACE training, supervision and the presence of a legal advisor. Journal of Investigative Psychology and Offender Profiling, 8, 149-162.

Davis, M. H. (1983). Measuring individual differences in empathy: Evidence for a multidimensional approach. Journal of Personality and Social Psychology, 44, $113-126$.

Davies, G. M., Westcott, H. L., \& Horan, N. (2000). The impact of questioning style on the content of investigative interviews with suspected child sexual abuse victims. Psychology, Crime \& Law, 6, 81-97. 
Dent, H.R. (1982). The effects of interviewing strategies on the results of interviews with childwitnesses. In A. Trankell (Ed.), Reconstructing the past (pp. 279-298). Deventer, The Netherlands: Kluwer.

Dent, H.R. (1986). An experimental study of the effectiveness of different techniques of questioning mentally handicapped child witnesses. British Journal of Clinical Psychology, 25, 13-17.

Dent, H. R., \& Stephenson, G. M. (1979). An experimental study of the effectiveness of different techniques of questioning child witnesses. British Journal of Social and Clinical Psychology, 18, 41-51.

Dickson, D., \& Hargie, O. (2006). Questioning. In O. Hargie (Ed.), The handbook of communication skills (pp. 121-145). Sussex: Routledge.

Gladstein, G. A. (1983). Understanding empathy: Integrating counselling, developmental and social psychology perspectives. Journal of Counselling Psychology, 30, 467-482.

Greenson, R. R. (1967). The technique and practice of psychoanalysis (Vol. 1). New York: International Universities Press.

Griffiths, A., \& Milne, R. (2006). Will it all end in tiers? Police interviews with suspects in Britain. In T. A. Williamson (Ed.), Investigative Interviewing: Rights, Research, Regulation (pp.167-189). Devon: Willan. 
Gudjonsson, G. H. (2006). Sex offenders and confessions: How to overcome their resistance during questioning. Journal of Clinical Forensic Medicine, 13, 203-207.

Holmberg, U., \& Christianson, S. (2002). Murderers' and sexual offenders experiences of police interviews and their inclination to admit or deny crimes. Behavioral Sciences \& the Law, 20, 31-45.

Holmberg, U. (2004). Police interviews with victims and suspects of violent and sexual crimes: Interviewee's experiences and interview outcomes. Unpublished PhD thesis, Stockholm University, 2004).

Hutcheson, G. D., Baxter, J. S., Telfer, K., \& Warden, D. (1995). Child witness statement quality: Question type and errors of omission. Law and Human Behavior, 19, 631648.

Jolliffe, D., \& Farrington, D. P. (2004). Empathy and offending: A systematic review and meta-analysis. Aggression and Violent Behaviour, 9, 441-476.

Kebbell, M., Hurren, E. J., \& Mazerolle, P. (2006). Sex offenders' perceptions of how they were interviewed. Canadian Journal of Police \& Security Services, 4, 67-75.

Kebbell, M., Alison, L., \& Hurren, E. (2008). Sex offenders' perceptions of the effectiveness and fairness of humanity, dominance, and displaying an understanding of cognitive distortions in police interviews: A vignette study. Psychology, Crime \& Law, 14, 435-449. 
Korkman, J., Santtila, P., \& Sandnabba, N. K. (2006) Dynamics of verbal interaction between interviewer and child in interviews with alleged victims of child sexual abuse. Scandinavian Journal of Psychology 47, 109-119.

Lamb, M.E., \& Fauchier, A. (2001). The effects of question type on self-contradictions by children in the course of forensic interviews. Applied Cognitive Development, 15, 483-491.

Lamb, M. E., Hershkowitz, I., Sternberg, K. J., Boat, B. W., \& Everson, M. D. (1996). Investigative interviews of alleged sexual abuse victims with and without anatomical dolls. Child Abuse and Neglect, 20, 1251-1259.

Larden, M., Melin, L., Holst, U., \& Langstrom, N. (2006). Moral judgement, cognitive distortions and empathy in incarcerated delinquent and community control adolescents. Psychology, Crime \& Law, 12, 453-462.

Loftus, E. (1982). Interrogating eyewitnesses - good questions and bad. In R. Hogarth (Ed.), Question framing and response consistency, San Francisco: Josey-Bass.

Milne, R., \& Bull, R. (1999). Investigative interviewing: Psychology and practice. Chichester: Wiley.

Milne, R., \& Bull, R. (2003). Does the cognitive interview help children to resist the effects of suggestive questioning? Legal and Criminological Psychology, 8, 21-38. 
Milne, R., \& Bull, R. (2006). Interviewing victims of crime, including children and people with intellectual difficulties. In M. R. Kebbell \& G. M. Davies (Eds.), Practical psychology for forensic investigations. Chichester: Wiley.

Mitchell-Gibbs, J., \& Joseph, S. (1996). Occupational trauma in the British police: Preliminary analysis. Issues in Criminological \& Legal Psychology, 25, 54 -58.

Moston, S., Stephenson, G. M., \& Williamson, T. A. (1993). The incidence, antecedents, and consequences of the use of the right to silence during police questioning. Criminal Behaviour and Mental Health, 3, 30-47.

Myklebust, T. (2009). Analysis of field investigative interviews of children conducted by specially trained police investigators. Unpublished $\mathrm{PhD}$ thesis. University of Oslo: Department of Psychology, Faculty of Social Sciences.

Myklebust, T., \& Bjørklund, R. A. (2006). The effect of long-term training on police officers' use of open and closed questions in field investigative interviews of children (FIIC). International Journal of Investigative Psychology and Offender Profiling, 3, $165-181$.

Myklebust, T., \& Bjørklund, R. A. (2009). The child verbal competence effect in court: A comparative study of field investigative interviews of children in child sexual abuse cases. Journal of Investigative Psychology and Offender Profiling, 6, 117-128.

Orbach, Y., \& Lamb, M.E. (2001). The relationship between within-interview contradictions and eliciting interviewer utterances. Child Abuse and Neglect, 25, 323-333. 
Oxburgh, G. E., Williamson, T. A., \& Ost, J. (2006). Police officers' use of negative emotional language during child sexual abuse investigations. International Journal of Investigative Psychology and Offender Profiling, 3, 35-45.

Oxburgh, G.E., Myklebust, T., \& Grant, T. (2010). The question of question types in police interviews: A review of the literature from a psychological and linguistic perspective. International Journal of Speech, Language and the Law, 17, 45-66.

Oxburgh, G. E., \& Ost, J. (2011). The Use and Efficacy of Empathy in Police Interviews with Suspects of Sexual Offences. Journal of Investigative Psychology and Offender Profiling , 8, 178-188.

Oxburgh, G. E., Ost, J. \& Cherryman, J. (2012). Police interviews with suspected child sex offenders: does use of empathy and question type influence the amount of investigation relevant information obtained? Psychology, Crime and Law, 18, 259273.

Oxburgh, G. E., Ost, J., Morris, P., Cherryman, J. (2013). Police officers’ perceptions of interviews in cases of sexual offences and murder involving children and adult victims. Police Practice \& Research: An International Journal (http://dx.doi.org/10.1080/15614263.2013.849595). First published on-line on 13 Oct 13. 
Pearlman, L.A., \& MacIan, P.S. (1993). Vicarious traumatization among trauma therapists: Empirical findings on self-care. Traumatic Stress Points: News for the International Society for Traumatic Stress Studies, 7, 5.

Phillips, E. C., Oxburgh, G. E., Gavin, A., \& Myklebust, T. (2011). Investigative interviews with victims of child sexual abuse: The relationship between question and investigation relevant information. Journal of Police and Criminal Psychology, 27, $45-54$

Pipe, M. A., Lamb, M. E., Orbach, Y., \& Esplin, P. W. (2004). Recent research on childrens' testimony about experienced and witnessed events. Developmental Review, 24, 440468.

Powell, M. B., \& Snow, P. C. (2007). Guide to questioning children during the free-narrative phase of an investigative interview. Australian Psychologist, 42, 57-65.

Preston, S. D., \& de Waal, B. M. (2002). Empathy: Its ultimate and proximate bases. The Behavioral and Brain Sciences, 25, 1-72.

Rich, K., \& Seffrin, P. (2012). Police interviews of sexual assault reporters: Do attitudes matter? Violence and Victims, 27, 263-279.

Saakvitne, K. W., \& Pearlman, L. A. (1996). Transforming the pain: A workbook on vicarious traumatisation. Behavioural Sciences and the Law.

Shepherd, E. (1991). Ethical interviewing. Policing, Vol. 7, 42-60. 
Shepherd, E. (2007). Investigative interviewing: The conversation management approach. Oxford: Oxford University Press.

Shepherd, E., \& Griffiths, A.G. (2013). Investigative interviewing: The conversation management approach ( $2^{\text {nd }}$ Ed.). Oxford: Oxford University Press.

Soukara, S., Bull, R., \& Vrij, A. (2002). Police detectives' aims regarding their interviews with suspects: Any change at the turn of the millenium? International Journal of Police Science and Management, 4, 101-114.

Sternberg, K.J., Lamb, M.E., Esplin, P.W., Orbach, Y., \& Hershkowitz, I. (2002). Using a Structured Interview Protocol to Improve the Quality of Investigative Interviews. In M.L. Eisen, J.A. Quas, \& G.S. Goodman (Eds.), Memory and Suggestibility in the Forensic Interview (pp. 409-436). London: Lawrence Erlbaum Associates, Publishers.

Walsh, D. \& Oxburgh, G. E. (2008). Investigative interviewing of suspects: historical and contemporary developments in research. Forensic Update (92), Winter 2007/8 (Feb 08), $41-45$.

Williamson, T. A. (1993). From interrogation to investigative policing: Strategic trends in police questioning. Journal of Community and Applied Social Psychology, 3, 89-99.

Yuille, J. C., \& Cutshall, J. L. (1986). A case study of eyewitness memory of a crime. Journal of Applied Psychology, 71, 291 - 301. 